удК $330.131 .7: 69$

Г. В. Хомкалов

Байкальский государственный университет, 2. Иркутск, Российская Федерация

Е. И. Кельберг

Байкальский государственный университет, г. Иркутск, Российская Федерация

\title{
УПРАВЛЕНИЕ ВАЛЮТНЫМИ РИСКАМИ В ИНВЕСТИЦИОННО-СТРОИТЕЛЬНОЙ ДЕЯТЕЛЬНОСТИ
}

\begin{abstract}
АНнотАЦия. В последнее время все большее влияние на различные отрасли экономики оказывает валютный риск. Традиционно считается, что данному виду риска подвержены лишь компании финансового сектора. Однако, статистические данные, приведённые в данной статье, доказывают непосредственное влияние и на компании инвестиционно-строительной отрасли.

Отсутствие системы управления валютным риском не только отражается на текущей деятельности предприятия, но и снижает точность прогнозирования основных показателей.

В данной статье рассматриваются особенности управления валютными рисками в организациях инвестиционно-строительной отрасли. Нами были подробно рассмотрены этапы управления валютными рисками. Особое внимание уделено идентификации валютного риска. Далее рассмотрены методы управления валютными рисками, предложен алгоритм хеджирования валютных рисков и метод их оценки на основе показателя Value at Risk.
\end{abstract}

кЛючЕВЫЕ слОВА. Валютный риск; управление рисками; хеджирование; деривативы.

ИНФОРМАЦИЯ О СТАТЬЕ. Дата поступления 16 июля 2017 г.; дата принятия к печати 11 октября 2017 г.; дата онлайн-размещения 25 октября 2017 г.

\author{
G. V. Khomkalov \\ Baikal State University, \\ Irkutsk, Russian Federation \\ E. I. Kelberg \\ Baikal State University, \\ Irkutsk, Russian Federation
}

\section{MANAGEMENT OF FOREIGN EXCHANGE RISKS IN INVESTMENT-CONSTRUCTION ACTIVITIES}

\begin{abstract}
In recent years, currency risk has exerted an increasing influence on various sectors of the economy. Traditionally, it is believed that only the financial sector companies are exposed to this type of risk. However, the statistics given in this article also proves the direct impact on the companies of the investment and construction industry. Absence of the currency risk management system not only impacts on the current activity of the enterprise, but also reduces the forecasting accuracy for the main indicators. The article examines the peculiarities of currency risk management in organizations of the investment and construction industry. We have examined in detail the stages of managing currency risks. Particular attention is paid to identifying the currency risk. Consideration is given to methods of currency risk management, while offering the hedging algorithm for currency risks and a method of their estimation based on the Value at Risk indicator.

KEYWORDS. Currency risk; risk management; hedging; derivatives.
\end{abstract}

\section{Baikal Research Journal}


ARTICLE INFO. Received July 16, 2017; accepted October 11, 2017; available online October 25, 2017.

Резкое снижение цен на нефть в 2014 г. и введение санкций из-за произошедших событий на Украине привело к ослаблению рубля по отношению к иностранной валюте. Следствием ослабления рубля стал рост инфляции, изменение уровня потребительского спроса, снижение доходов населения. Так, 16 декабря 2014 г. курсы доллара и евро составили 79 и 98 р. Центральный банк был вынужден повысить ключевую ставку до 17 \%, что привело к повышению стоимости заемных средств. По итогам 2014 г. рубль потерял 58 \% своей стоимости. Рекордное ослабление рубля с 1998 г. произошло в декабре 2015 г., доллар и евро стоили 71 и 78 р. Все эти события привели к снижению потребительского спроса.

В трудное положение попали и заемщики, которые брали кредиты в иностранной валюте.

Ослабление рубля по отношению к иностранной валюте негативно сказалось и на инвестиционно-строительной отрасли. По данным исследования влияние курса рубля на экономическую активность России [1] «девальвация оказывает негативное влияние на рост строительной отрасли, что свидетельствует об отрицательном эффекте падения курса на инвестиции». Связано это со снижением потребительского спроса и инвестиционной привлекательности, удорожанием себестоимости строительства и кредитов, доступностью ипотечного кредитования, снижением реальных доходов населения в результате инфляционных процессов. Поэтому все более актуальным становиться управление валютными рисками. Считается, что данному виду риска подвержены в основном финансовые организации. Так, в соответствии с наиболее полной классификацией рисков инвестиционно-строительной отрасли, приведенной в [2], различают следующие виды рисков.

1. Риски внутренней среды, к которым относятся: производственные, технологические, экономические, социальные маркетинговые, инновационные, организационные, специфические, инновационные.

2. Риски внешней среды: политические, общеэкономические, правовые, социальные, отраслевые, климатические и экологические.

Как видно из представленной классификации, валютные риски относительно инвестиционно-строительной отрасли отдельно не рассматриваются, а входят в группу общеэкономических рисков.

Для понимания значения валютных рисков, необходимо дать их определение. Надо отметить, что в большинстве случаев валютный риск понимается как вероятность изменения курса валюты и никак не связан с деятельностью органов государственного управления и организации.

В ряде словарей определение валютного риска представлено как влияние валютного курса на прибыльность сделки в период между заключением контракта и его выполнением.

В статье «Валютный риск: от определения к классификации» [3] дано следующее определение: «валютный риск - это вероятность реализации одного или нескольких событий в связи с изменением курсов валют или действиями органов государственной власти, объектом которых являются валютные ценности, приводящие к положительному или отрицательному изменению экономического положения субъекта предпринимательской деятельности».

На наш взгляд, определение, приведенное в [3] наиболее полно отражает природу валютного риска, так как учитывает его спекулятивный характер, в то вре-

\section{Baikal Research Journal}

электронный научный журнал Байкальского государственного университета 
мя, как в большинстве источников данный тип риска характеризуется с точки зрения опасности.

Самая популярная на данный момент классификация валютных рисков принадлежит Шапиро [4, с. 332-333], согласно данной классификации валютные риски делятся наследующие виды:

- транзакционные (позиционные, операционные или риски сделки);

- трансляционные (консолидированные или риски при объединении);

- экономические (или рыночные) риски.

Первый вид рисков возникает при прямом воздействии колебания курса валют на денежный поток. Например, во многих регионах России рынок недвижимости является бивалютным. Поэтому колебания курса валют могут создавать разнонаправленную динамику цен на рынке.

Трансляционные риски возникают при необходимости оценки эффективности международной организации, включая дочерние предприятия.

Экономические риски могут воздействовать на компании, которые напрямую не подвержены влиянию валютного риска. Проявляется данный вид риска в уменьшении товарооборота, изменении цен на продукцию, материалы и др.

Необходимость совершенствования системы управления валютным риском подтверждается выборочным обследованием деловой активности строительных организаций ${ }^{1}$, которое проводилось по состоянию на 10 февраля 2017 г. В нем приняли участие 6,5 тыс. строительных организаций, различных по численности занятых и формам собственности, в том числе 4,3 тыс. субъектов малого предпринимательства (без микропредприятий).

В I квартале 2017 г. руководители 72 \% строительных организаций оценили экономическую ситуацию в строительстве как «удовлетворительную», 19 \% как «неудовлетворительную» и 9 \% - как «благоприятную».

Во II квартале 2017 г. $73 \%$ руководителей строительных организаций не ожидают ее изменения, $19 \%$ - считают, что экономическая ситуация в строительстве улучшится, 8 \% - ожидают ее ухудшения ${ }^{2}$.

При реализации инвестиционно-строительных проектов основным источником неопределенности является цена на готовую продукцию и строительные материалы. Так, согласно данным Федеральной службы государственной статистики (http://www.gks.ru/free_doc/new_site/business/stroit/stroi29g.htm) основными факторами, ограничивающими производственную деятельность строительных организаций (рис. 1), являются:

- высокий уровень налогов (на этот фактор указали 35 \% опрошенных руководителей организаций);

- недостаток заказов на работы (34 \%);

- высокая стоимость материалов, конструкций, изделий (30 \%).

Высокая стоимость материалов, конструкций, изделий зачастую является следствием воздействия экономического валютного риска. Ввиду длительного срока реализации инвестиционно-строительных проектов, цена на материалы является трудно прогнозируемой величиной, имеющей тенденцию к росту. Такой вывод был сделан на основе анализа данных Федеральной службы статистики, представленных в табл. 1.

\footnotetext{
${ }^{1}$ Строительство / Федеральная служба государственной статистики. URL: http://www.gks.ru/ wps/wcm/connect/rosstat_main/rosstat/ru/statistics/enterprise/building/\#/

${ }_{2}^{2}$ Там же.
}

\section{Baikal Research Journal}


Высокий уровень налогов

Недостаток заказов на работы

Высокая стоимость материалов, конструкций, изделий

Неплатежеспособность заказчиков

Недостаток финансирования

Конкуренция со стороны других строительных фирм

Высокий процент коммерческого кредита

Погодные условия

Недостаток квалифицированных рабочих

Недостаток материалов

Нехватка и изношенность машин и механизмов

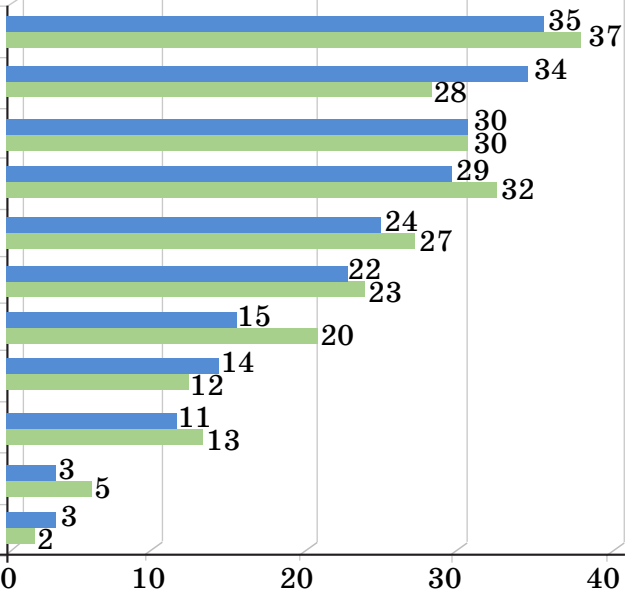

І І квартал 2017 І квартал 2016

Рис. 1. Факторы, ограничивающие производственную деятельность строительных предприятий (по материалам выборочного обследования)

Таблица 1

Индексы иен на приобретенные строительными организациями основные виды материалов

\begin{tabular}{|c|c|c|c|c|c|c|c|c|c|c|c|}
\hline \multirow{2}{*}{ Наименование } & \multicolumn{11}{|c|}{ Года } \\
\hline & 2006 & 2007 & 2008 & 2009 & 2010 & 2011 & 2012 & 2013 & 2014 & 2015 & 2016 \\
\hline $\begin{array}{l}\text { Панели стеновые } \\
\text { наружные железобе- } \\
\text { тонные }\end{array}$ & 115,9 & 127,8 & 115,7 & 97,8 & 103,9 & 110,5 & 108,1 & 103,6 & 105,8 & 102,1 & 104,9 \\
\hline $\begin{array}{l}\text { Бетон, готовый для } \\
\text { заливки (товарный } \\
\text { бетон) }\end{array}$ & 115,6 & 136,8 & 119,7 & 82,9 & 97,8 & 115,8 & 101,7 & 102 & 100,1 & 101 & 101,3 \\
\hline Кирпич силикатный & 115,2 & 121,8 & 121,4 & 98,6 & 99,9 & 108,7 & 106 & 105,1 & 102,4 & 105,5 & 102,1 \\
\hline Щебень & 117,8 & 122,3 & 118,2 & 92,3 & 105,6 & 117,1 & 108,8 & 100,7 & 99,5 & 103,4 & 105,8 \\
\hline $\begin{array}{l}\text { Пески природные } \\
\text { прочие }\end{array}$ & 119,9 & 118,6 & 124,8 & 95,6 & 100 & 111,8 & 109 & 105,2 & 100,6 & 102,9 & 103,8 \\
\hline $\begin{array}{l}\text { Пиломатериалы } \\
\text { обычные, не вклю- } \\
\text { ченные в другие } \\
\text { группировки, прочие }\end{array}$ & 113,1 & 124,9 & 115 & 97,4 & 108,6 & 106,1 & 103,2 & 102,8 & 104,3 & 105 & 103,5 \\
\hline $\begin{array}{l}\text { Листы асбестоце- } \\
\text { ментные волнистые } \\
\text { (гофрированные) } \\
\text { (шифер) }\end{array}$ & 108,7 & 120,3 & 109,7 & 100,4 & 99,2 & 101,4 & 102,2 & 102,2 & 99,6 & 102 & 103,6 \\
\hline Электроэнергия & 107,4 & 110,5 & 115,9 & 118,1 & 117,2 & 110,7 & 103 & 107 & 105,6 & 110 & 106,3 \\
\hline $\begin{array}{l}\text { Окна и их коробки, } \\
\text { подоконники поли- } \\
\text { мерные }\end{array}$ & $\ldots$ & $\cdots$ & $\cdots$ & $\ldots$ & 102,2 & 103 & 104,5 & 96,3 & 100,5 & 102,7 & 104,1 \\
\hline $\begin{array}{l}\text { Радиаторы цен- } \\
\text { трального отопле- } \\
\text { ния с неэлектриче- } \\
\text { ским нагревом из } \\
\text { черных металлов }\end{array}$ & $\ldots$ & $\cdots$ & $\cdots$ & $\ldots$ & 103 & 108,1 & 107,5 & 94,1 & 101,1 & 108,3 & 100,6 \\
\hline $\begin{array}{l}\text { Смесь песчано-гра- } \\
\text { вийная }\end{array}$ & $\cdots$ & $\cdots$ & $\cdots$ & $\cdots$ & 106,1 & 119,2 & 111,8 & 104,2 & 98,4 & 101 & 102,4 \\
\hline
\end{tabular}

\section{Baikal Research Journal}


Колебания цен на строительные материалы существенным образом оказывают влияние на стоимость готовой продукции в связи с тем, что являются основными затратами [5] (табл. 2).

Структура затрат на производство строительных работ

Таблица 2

в Российской Федерации по фактической себестоимости; в процентах к итогу по данным на 15 марта 2017 г.

\begin{tabular}{|c|c|c|c|c|c|c|c|c|c|c|c|}
\hline \multirow{2}{*}{ Наименование } & \multicolumn{11}{|c|}{ Года } \\
\hline & 2005 & 2006 & 2007 & 2008 & 2009 & 2010 & 2011 & 2012 & 2013 & 2014 & 2015 \\
\hline Все затраты & 100 & 100 & 100 & 100 & 100 & 100 & 100 & 100 & 100 & 100 & \begin{tabular}{|l}
0 \\
0
\end{tabular} \\
\hline \multicolumn{12}{|l|}{$\begin{array}{l}\text { в том числе } \\
\text { по элементам }\end{array}$} \\
\hline материальные затраты & 57,4 & 58,7 & 59,7 & 59,4 & 56,9 & 56,3 & 57,4 & 55,2 & 56,1 & 58,3 & 60,0 \\
\hline затраты на оплату труда & 21,1 & 20,4 & 19,6 & 19,6 & 19,2 & 20,2 & 19,1 & 18,8 & 18,9 & 20,0 & 18,2 \\
\hline $\begin{array}{l}\text { страховые взносы в } \\
\text { Пенсионный фонд, ФСС, } \\
\text { ФФОМС1). }\end{array}$ & 5,0 & 4,6 & 4,3 & 4,1 & 4,0 & 4,2 & 5,0 & 4,8 & 4,8 & 5,2 & 4,9 \\
\hline $\begin{array}{l}\text { амортизация основных } \\
\text { средств }\end{array}$ & 2,4 & 2,5 & 2,0 & 2,1 & 2,7 & 2,9 & 2,6 & 2,8 & 2,8 & 3,1 & 2,9 \\
\hline прочие затраты & 14,1 & 13,8 & 14,4 & 14,8 & 17,2 & 16,4 & 15,9 & 18,4 & 17,4 & 13,4 & 14,0 \\
\hline
\end{tabular}

В январе 2017 г. компанией одной из крупнейших аудиторско-консалтинговых фирм КМПГ был подготовлен «Обзор затрат на строительство и строительные материалы в России" [5]. Авторы данного исследования выделяют валютные риски одним из основных факторов изменения себестоимости строительства в 20142016 гг. (см. рис. 2).

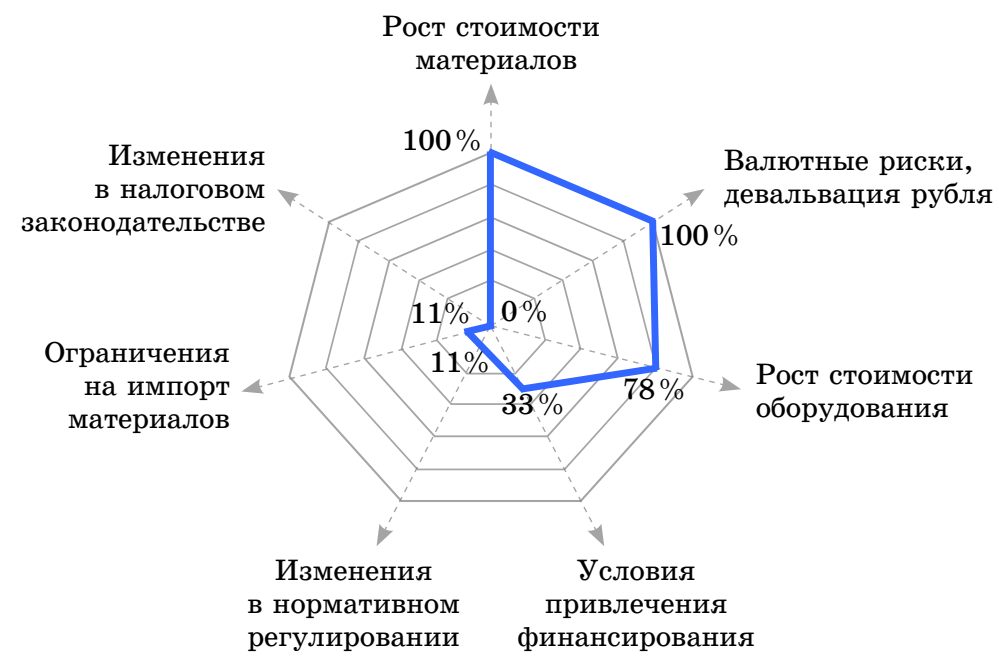

—— Доля компаний, считающих данный фактор значимым

Рис. 2. Основные факторы изменения себестоимости строительства в 2014-2016 г2.

\section{Baikal Research Journal}


Импортные строительные материалы подорожали на 42 \% в 2015 г., объем импорта снизился на $14 \%$ (рис. $3-4$ ).

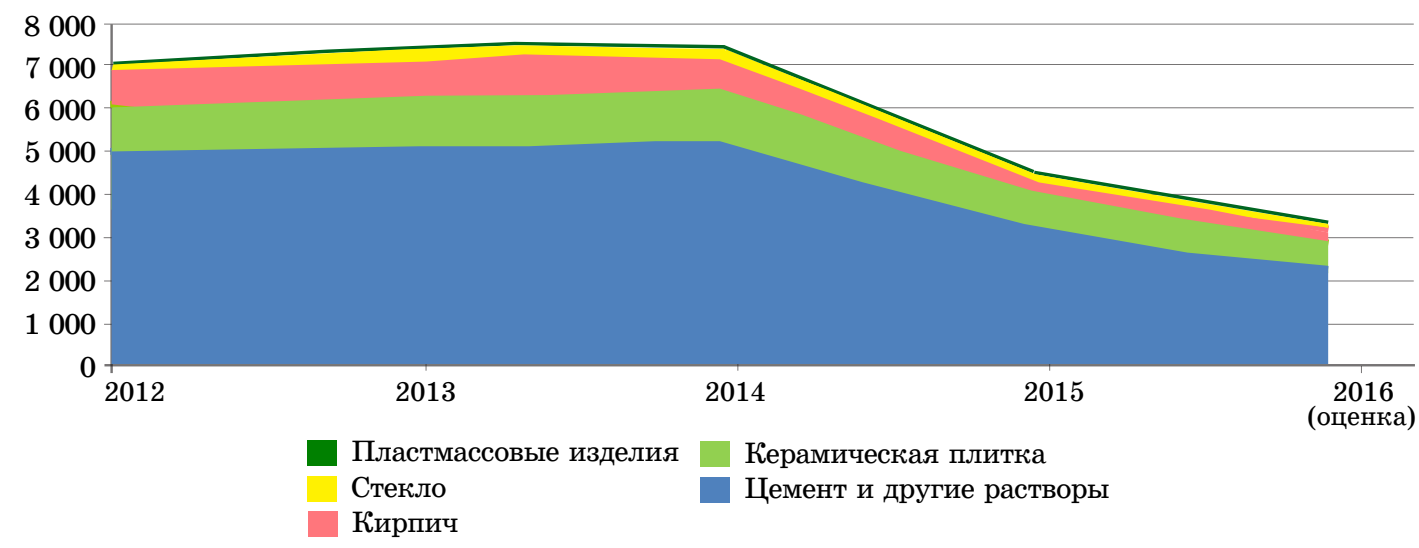

Рис. 3. Динамика и структура импорта строительных материалов в РФ, тыс. $m$

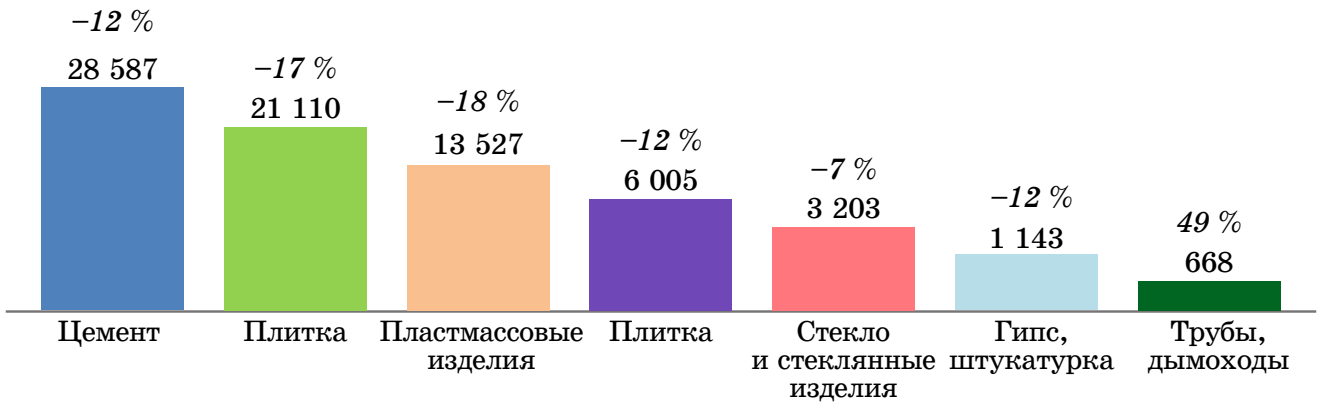

Рис. 4. Объем илпорта строительных материалов в РФ 2015 г., млн р., и изменение объема импорта к 2014 г., \%

Рост стоимости строительных материалов обусловлен влиянием различных факторов, но основным из них является валютный риск.

В связи с вышеизложенными фактами компании инвестиционно-строительной отрасли должны осуществлять непрерывное управление валютными рисками. Наличие системы управления рисками позволит не только минимизировать валютный риск, но будет способствовать оптимизации внутренних процессов организации.

Вне зависимости от вида риска выделяют следующие этапы менеджмента риска: идентификация, анализ и оценка, разработка политики по управлению риском, реализация и мониторинг. Рассмотрим детально процесс управления валютными рисками по представленным этапам.

На этапе идентификации риска анализируется деятельность компании и выявляется источник возникновения валютного риска. Для качественной идентификации рисков необходимо знать особенности жизненного цикла инвестиционно-строительного проекта. Выделяют три этапа жизненного цикла проекта: прединвестиционный, инвестиционный, этап эксплуатации построенного объекта [6;7]. Для более четкой идентификации каждый этап разделяют на несколько уровней реализации.

\section{Baikal Research Journal}


Особенное место в реализации проекта имеет прединвестиционный этап. Именно в ходе реализации данного этапа риск - менеджмент вызывает больше всего трудностей. Необходимо выявить все источники неполучения желаемого результата, а также последствия наступления неблагоприятного события. В результате идентификации рисков на прединвестиционном этапе строятся сценарии реализации инвестиционно-строительного проекта.

Качественной идентификации рисков способствует наличие ретроспективной информации о реализации аналогичных проектов в компании или же отрасли в целом. Именно анализ ретроспективной информации позволит выявить источник возникновения валютного риска и оценить его воздействие не реализацию проекта. Источники возникновения валютного риска можно разделить на внешние, $\kappa$ которым относятся колебания валютного курса и действия органов государственной власти и внутренние, к которым можно отнести организационные и управленческие.

Отнюдь не всегда необходимо принимать меры для управления риском: стоимость управления риском может оказаться выше потенциальной угрозы от его реализации, а потенциальные потери могут оказаться соизмеримы с величиной риск-аппетита. Риск-аппетит определяет уровень риска, на который компания готова пойти для достижения поставленных целей.

Для того, чтобы приступить к идентификации нужно проанализировать исходную информацию. Для анализа используются следующие методы: метод Дельфи, мозговой штурм, метод номинальных групп, карточки Кроуфорда, опросы экспертов, идентификация основной причины, анализ SWOT, анализ контрольных списков, метод аналогии, метод диаграмм.

Результатом идентификации рисков является их подробное описание в установленной форме. Форма может быть утверждена организацией или же принята в соответствии со стандартами управления рисками, например, стандартами FERMA, COSE ERM или ISO 31000:2009.

На этапе анализа и оценки рисков выбираются ключевые показатели, а также разрабатываются инструменты для оценки валютного риска.

В настоящее время чаще всего применяют следующие виды анализа и оценки рисков: статистический; экспертных оценок; аналитический; оценки финансовой устойчивости и платежеспособности; оценки целесообразности затрат; анализ последствий накопления риска; метод использования аналогов; комбинированный метод.

Наиболее эффективным методом измерения количественного уровня валютного риска является методология Value at Risk (VaR). VaR - статистический подход основным понятием которого является распределение вероятностей, связывающее все возможные величины изменений рыночных факторов с вероятностями их наступления [8]. VaR определяет величину максимально возможных потерь на заданном временном горизонте.

Среди методов расчета VaR различают: параметрический, метод исторического моделирования, метод Монте Карло. Все перечисленные методы расчета имеют схожую структуру:

1) вычисление рыночной стоимости актива или интенсивности роста котировок, курса валют;

2) оценка вероятностного распределения доходности актива, волиатильности котировок, курса валют;

3) выбор доверительного уровня и соответствующего ему значения VaR.

\section{Baikal Research Journal}


Параметрический метод расчета основан на нормальном распределении вероятностей и это является его главным недостатком. Данный метод подходит для оценки риска актива с линейными характеристиками.

Метод исторического моделирования, в отличии от параметрического, позволяет оценить активы с нелинейными характеристиками. Кроме того, он основан на ретроспективных данных, что повышает его точность.

Метод Монте Карло является самым сложным методом определения VaR. B данном методе появляется возможность использовать любые распределения. В соответствии с ретроспективными данными рассчитываются волиатильность и математическое ожидание, затем рассчитываются моделируемые данные и производится переоценка актива.

Для компаний инвестиционно-строительной отрасли основной опасностью является снижение денежного потока, поэтому измерение VaR целесообразно заменить на измерение денежного потока в условиях риска - C-FaR. Для расчета C-FaR необходим более длительный период прогнозирования - до двадцати кварталов. Основным преимуществом C-FaR перед VaR является то, что для вычисления используются не только финансовые факторы риска, но и те факторы, которые являются значимыми для конкретной компании: изменение цен на продукцию, материалы, уровень цен конкурирующих организаций и др.

После идентификации, анализа и оценки уровня риска необходимо выбрать метод управления валютным риском и разработать политику по управлению риском. Выбранная политика должна учитывать уровень риск-аппетита в соответствии с выбранным лимитом валютного риска.

Среди методов управления рисками различают:

1) методы локализации рисков;

2) методы диверсификации рисков;

3) методы компенсации рисков;

4) методы уклонения от рисков.

Методы локализации рисков используются только в случае, если возможна четкая идентификация, определение причин и источника возникновения риска.

Методы диверсификации рисков предполагают распределение риска между участниками, распределение по видам деятельности, диверсификацию сбыта и поставок, инвестиций, кредитов, а также распределение риска по этапам проекта или по времени.

Методы компенсации рисков направлены на разработку системы предупреждения опасности и включают: создание резервов, прогнозирование, мониторинг деятельности и др.

Методы уклонения от рисков используются в случае, если организация предпочитает действовать «наверняка» и включают: отказ от ненадежных партнеров, поиск гарантов, страхование рисков, передача риска (контрагенту, на аутсорсинг), хеджирование рисков.

Особую роль среди методов управления валютными рисками занимает хеджирование. Существует ряд исследований $[9 ; 10 ; 11 ; 12]$, в которых статистически доказано положительное влияние хеджирования на стоимость компании. Например, исследование, проведенное Allayannis и Miller, в котором приняли участие 1546 компаний нефинансового сектора, доказывает, что те компании, которые подвержены валютному риску и используют деривативы для хеджирования, в среднем увеличивают стоимость компании на $10,7 \%$.

Хеджирование - это страхование, снижение риска от потерь, обусловленных неблагоприятными для продавцов или покупателей изменениями цен на товары в сравнении с теми, которые учитывались при заключении договора [13].

\section{Baikal Research Journal}

электронный научный журнал Байкальского государственного университета 
К преимуществам хеджирования относят:

1) снижение уровня ценового риска. Например, если предполагается рост цен на строительные материалы, то хеджирование будет способствовать закреплению текущих цен;

2) увеличение стабильности и возможности планирования и прогнозирования. Инвестиционно-строительные проекты отличаются длительными сроками реализации, поэтому показатели, рассчитанные на этапе планирования проекта, всегда отличаются от показателей на стадии реализации.

Одним из основных инструментов хеджирования валютных рисков являются деривативы или производные финансовые инструменты. Деривативы - это финансовые инструменты, такие как финансовые опционы, фьючерсные и форвардные контракты, процентные и валютные свопы, порождающие права и обязанности, исполнение которых ведет к передаче от одной стороны финансового инструмента к другой одного или более финансовых рисков, присущих базисному финансовому инструменту [14].

Для осуществления хеджирования валютных рисков необходимо определить этапы данного процесса.

1. Определение целей хеджирования. Цели хеджирования должны быть сопоставимы с целями реализации инвестиционно-строительного проекта.

2. Установление размера хеджируемой позиции. Данный этап включает в себя идентификацию валютного риска, его анализ и оценку, а также определение склонности к риску и риск-аппетита.

3. Выбор рынка и методов управления рисками. В зависимости от того на биржевом или внебиржевом рынке планирует осуществлять хеджирование определяется стратегия. Выбор метода хеджирования зависит от ряда факторов: размера риска и риска-аппетита, вероятности возникновения риска, возможности прогнозирования, возможности идентификации риска и прочих $[14$, с. 35$]$.

4. Планирование хеджирования и определение стоимости выбранного инструмента.

5. Мониторинг и контроль. В связи с постоянным изменением внешней и внутренней среды организации выбранная политика по управлению валютным риском должна подвергаться постоянному мониторингу, контролю и пересмотру.

В результате проведенного анализа можно сделать вывод о том, что хеджирование является эффективным инструментом управления рисками, в том числе, и для компаний инвестиционно-строительной отрасли. В дальнейшем необходима разработка методики, которая позволила бы обобщить и систематизировать подходы к хеджированию валютных рисков и была бы адаптирована для применения компаниями нефинансового сектора.

Проблемной областью исследований является установление зависимости влияние хеджирования на стоимость компаний в связи с тем, что недостаточно статистических данных для анализа. Кроме того, хеджирование ограничивает отсутствие методов бухгалтерского и налогового учета операций.

\section{Список использованной литературы}

1. Бадасен П. В. Эконометрическая оценка влияния валютного курса рубля на динамику / П. В. Бадасен // Деньги и кредит. - 2015. - № 7. - С. 41-49.

2. Доронкина Л. Н. Управление инвестиционными рисками в строительстве : автореф. дис. д-ра. экон. наук / Л. Н. Доронкина. - М., 2007. - 42 с.

3. Дмитриев М. А. Валютный риск: от определения к классификации / М. А. Дмитриев // Российское предпринимательство. - 2015. - Т. 16, № 15. - С. 2423-2436.

\section{Baikal Research Journal}


4. Shapiro A. Multinational Financial Management / A. Shapiro. - Hoboken : John Wiley \& Sons, 2010. - $736 \mathrm{p}$.

5. Обзор затрат на строительство и строительные материалы в России [Электронный peсурс] / КПМГ в России и СНГ. - М., 2017. - Режим доступа: https://assets.kpmg.com/ content/dam/kpmg/ru/pdf/2017/01/ru-ru-building-materials-costs.pdf.

6. Недвижимость и строительство [Электронный ресурс] / КПМГ в России и СНГ. - М., 2017. - Режим доступа: https://home.kpmg.com/ru/ru/home/industries/real-estate.html.

7. Асаул А. Н. Интегративное управление в инвестиционно-строительной сфере / А. Н. Асаул, В. П. Грахов. - СПб. : Гуманистика, 2007. - 248 с.

8. Уфимцев А. А. Измерение валютных рисков с помощью методологии Value at Risk / А. А. Уфимцев // Вестник Челябинского государственного университета. — 2012. — № 8. Вып. 36. - С. 137-142.

9. Allayannis G. The Use of Foreign Currency Derivatives and Firm Market Value / G. Allayannis, J. Weston // Review of Financial Studies. — 2002. — № 14. — Pp. 243-276.

10. Allayannis, G. The Use of Foreign Currency Derivatives, Corporate Governance, and Firm Value Around The World / G. Allayannis, U. Lel, D. Miller // Journal of International Economics. - 2012. — № 87. — Pp. 65-79.

11. Bartram S. The Effects of Derivatives on Firm Risk and Value / S. Bartram, G. Brown, J. Conrad // Journal of Financial and Quantitative Analysis. — 2011. — № 46. Pp. 967-999.

12. Dhanani A. Why UK Companies Hedge Interest Rate Risk / A. Dhanani, S. Fifield, C. Helliar, L. Stevenson // Studies in Economics and Finance. -2007. - № 24. - Pp. 72-90.

13. Финансы и биржа : словарь терминов. 2013. [Электронный ресурс] // Академик. Режим доступа: http://finance_stock_exchange.academic.ru/.

14. Рэдхэд К. Управление финансовыми рисками / К. Рэдхэд, С. Хьюс. - М. : ИНФРА-М, 1996. - 288 с.

\section{References}

1. Badasen P. V. Econometric estimation of influence of rouble currency rate on dynamics. Den'gi i kredit = Money And Credit, 2015. no. 7, pp. 41-49. (In Russian).

2. Doronkina L. N. Upravlenie investitsionnymi riskami v stroitel'stve. Avtoref. Dokt. Diss. [Investment risk management in construction. Dokt. Diss. Thesis]. Moscov, 2007. 42 p.

3. Dmitriev M. A. Currency risk: from definition to classification. Rossiiskoe predprinimatel'stvo = Russian Entrepreneurship, 2015, vol. 16, no. 15, pp. 2423-2436. (In Russian). $736 \mathrm{p}$.

4. Shapiro A. Multinational Financial Management. Hoboken, John Wiley \& Sons, 2010.

5. Review of expenditures for construction and construction materials in Russia. Available at: https://assets.kpmg.com/content/dam/kpmg/ru/pdf/2017/01/ru-ru-building-materialscosts.pdf (In Russian).

6. Real estate and construction. Available at: https://home.kpmg.com/ru/ru/home/ industries/real-estate.html (In Russian).

7. Asaul A. N., Grakhov V. P. Integrativnoe upravlenie v investitsionno-stroitel'noi sfere [Integrative management in investment-construction sector]. Saint Petersburg, Gumanistika Publ, 2007. 248 p.

8. Ufimtsev A. A. Currency risk management using Value at Risk methodology. Vestnik Chelyabinskogo gosudarstvennogo universiteta = Bulletin of Chelyabinsk State University, 2012, no. 8, vol. 36, pp. 137-142. (In Russian).

9. Allayannis G., Weston J. The Use of Foreign Currency Derivatives and Firm Market Value. Review of Financial Studies, 2002, no. 14, pp. 243-276.

10. Allayannis, G., Lel U., Miller D. The Use of Foreign Currency Derivatives, Corporate Governance, and Firm Value Around The World. Journal of International Economics, 2012, no. 87, pp. 65-79.

11. Bartram S., Brown G., Conrad J., Helliar C. The Effects of Derivatives on Firm Risk and Value. Journal of Financial and Quantitative Analysis, 2011, no. 46, pp. 967-999.

12. Dhanani A., Fifield S., Helliar C., Stevenson L. Why UK Companies Hedge Interest Rate Risk. Studies in Economics and Finance, 2007, no. 24, pp. 72-90.

\section{Baikal Research Journal}


13. Finance and stock exchange: dictionary of terms. 2013. Available at: http://finance stock_exchange.academic.ru/ (In Russian).

14. Redkhed K., Kh'yus S. Upravlenie finansovymi riskami [Financial risk managemenet]. Moskov, INFRA-M Publ., 1996. 288 p.

\section{Информация об авторах}

Хомкалов Геннадий Владилирович - профессор, кафедра экономики и управления инвестициями и недвижимостью, Байкальский государственный университет, 664003, г. Иркутск, ул. Ленина, 11, e-mail: hgv1950@mail.ru.

Кельберг Елена Игоревна - аспирант, кафедра экономики и управления инвестициями и недвижимостью, Байкальский государственный университет, 664003, г. Иркутск, ул. Ленина, 11, e-mail: 762113@gmail.com.

\section{Authors}

Gennady V. Homkalov — PhD habil. in Economics, Chair of Economics and Management of Investments and Real Estate, Baikal State University, 11 Lenin St., 664003, Irkutsk; e-mail: hgv1950@mail.ru.

Yelena I. Kelberg - PhD Student, Chair of Economics and Management of Investments and Real Estate, Baikal State University, 11 Lenin St., 664003, Irkutsk; e-mail: 762113@ gmail.com.

\section{Для цитирования}

Хомкалов Г. В. Управление рисками в инвестиционно-строительной деятельности / Г. В. Хомкалов, Е. И. Кельберг // Baikal Research Journal. - 2017. - Т. 8. - № 3. - DOI : 10.17150/2411-6262.2017.8(3).7.

\section{For citation}

Homkalov G. V., Kelberg E. I. Management of foreign exchange risks in investmentconstruction activities. Baikal Research Journal, 2017, - Vol. 8. - №. 3. DOI : 10.17150/24116262.2017.8(3).7. (In Russian).

\section{Baikal Research Journal}

